\title{
Jasmonic acid is involved in the signaling pathway for fungal endophyte-induced volatile oil accumulation of Atractylodes lancea plantlets
}

\author{
Cheng-Gang Ren and Chuan-Chao Dai*
}

\begin{abstract}
Background: Jasmonic acid (JA) is a well-characterized signaling molecule in plant defense responses. However, its relationships with other signal molecules in secondary metabolite production induced by endophytic fungus are largely unknown. Atractylodes lancea (Asteraceae) is a traditional Chinese medicinal plant that produces antimicrobial volatiles oils. We incubated plantlets of A. lancea with the fungus Gilmaniella sp. AL12. to research how JA interacted with other signal molecules in volatile oil production.

Results: Fungal inoculation increased JA generation and volatile oil accumulation. To investigate whether JA is required for volatile oil production, plantlets were treated with JA inhibitors ibuprofen (IBU) and nordihydroguaiaretic acid. The inhibitors suppressed both JA and volatile oil production, but fungal inoculation could still induce volatile oils. Plantlets were further treated with the nitric oxide (NO)-specific scavenger 2-(4carboxyphenyl)-4,4,5,5-tetramethylimidazoline-1-oxyl-3-oxide potassium salt (CPTIO), the $\mathrm{H}_{2} \mathrm{O}_{2}$ inhibitors diphenylene iodonium (DPI) and catalase (CAT), and the salicylic acid (SA) biosynthesis inhibitors paclobutrazol and 2aminoindan-2-phosphonic acid. With fungal inoculation, IBU did not inhibit NO production, and JA generation was significantly suppressed by CPTIO, showing that JA may act as a downstream signal of the NO pathway. Exogenous $\mathrm{H}_{2} \mathrm{O}_{2}$ could reverse the inhibitory effects of CPTIO on JA generation, indicating that NO mediates JA induction by the fungus through $\mathrm{H}_{2} \mathrm{O}_{2}$-dependent pathways. With fungal inoculation, the $\mathrm{H}_{2} \mathrm{O}_{2}$ scavenger DPI/CAT could inhibit $J A$ generation, but IBU could not inhibit $\mathrm{H}_{2} \mathrm{O}_{2}$ production, implying that $\mathrm{H}_{2} \mathrm{O}_{2}$ directly mediated JA generation. Finally, JA generation was enhanced when SA production was suppressed, and vice versa.
\end{abstract}

Conclusions: Jasmonic acid acts as a downstream signaling molecule in NO- and $\mathrm{H}_{2} \mathrm{O}_{2}$-mediated volatile oil accumulation induced by endophytic fungus and has a complementary interaction with the SA signaling pathway.

Keywords: Atractylodes lancea, Endophytic fungi, Volatile oil, Jasmonic acid, Medicinal herb

\section{Background}

Atractylodes lancea, a member of the Compositae family, is a traditional Chinese medicinal plant $[1,2]$. Volatile oils from A. lancea show antimicrobial activities as well. These oils comprise active secondary metabolites, including the characteristic components atractylone, $\beta$ eudesmol, hinesol, and atractylodin [3]. Secondary metabolites, such as terpenes, flavonoids, and alkaloids, are believed to be involved in plant responses to many biotic

\footnotetext{
* Correspondence: daichuanchao@njnu.edu.cn

Jiangsu Engineering and Technology Research Center for Industrialization of Microbial Resources, Jiangsu Key Laboratory for Microbes and Functional Genomics, College of Life Science, Nanjing Normal University, Nanjing 210046, P.R. China
}

(c) 2012 Ren and Dai; licensee BioMed Central Ltd. This is an Open Access article distributed under the terms of the Creative Commons Attribution License (http://creativecommons.org/licenses/by/2.0), which permits unrestricted use, distribution, and reproduction in any medium, provided the original work is properly cited. and abiotic stresses [4-6]. Another plant defense response is the activation of multiple signaling events $[7,8]$. For example, jasmonic acid (JA) biosynthesis by plants is induced by pathogen infection and elicitor treatment [9], and salicylic acid (SA) is involved in activating distinct sets of defense-related genes [10], such as those that encode pathogenesis-related (PR) proteins [11]. Also, many signaling molecules have been revealed to be involved in secondary metabolism [12-14].

Endophytes can coexist with their hosts and have great potential to affect the hosts' metabolism [15]; their effects on plant accumulation of medicinal components have received much attention recently [16,17]. Unlike pathogens, endophytic fungi do not cause strong hypersensitive 
reactions in the host. But long-term colonization can induce various kinds of metabolites to accrue in hosts $[17,18]$. How endophytic fungus-host interactions affect the accumulation of plant secondary metabolites is an intriguing issue.

Jasmonic acid is a well-characterized plant signaling molecule that mediates plant defense responses [19] by responding to microbial infection and elicitor treatment [20]. Kunkel et al.. [21] found that fungal elicitor caused rapid increases in JA production, secondary metabolite biosynthetic gene expression, and secondary metabolite accumulation in many plants. Exogenous JA application enhanced gene expression of secondary metabolite biosynthetic pathways, while the fungal elicitor-induced secondary metabolite accumulation could be abolished by JA synthesis inhibitors [13]. Most plant defense responses are regulated by many signal molecules, and "cross-talk" among multiple signaling pathways is important in plant cell signal transduction networks [21]. An increasing number of studies have shown that these signals do not function entirely independently; rather, they are influenced the magnitude or amplitude of various other signals [22].

Although interactions between SA- and JA-mediated signaling pathways have been reported to enhance the expression of plant defense-related genes, studies on interactions between JA and multiple signaling pathways (nitric oxide, hydrogen peroxide, and SA) in mediating plant secondary metabolite accumulation are rare. In this work, we report that JA acts as a downstream signal of nitric oxide (NO)- and hydrogen peroxide $\left(\mathrm{H}_{2} \mathrm{O}_{2}\right)$ mediated volatile oil accumulation in A. lancea plantlets induced by endophytic fungus Gilmaniella sp. AL12. Furthermore, we reveal an unusual complementary relationship between JA and SA in mediating the biosynthesis of medicinal plant secondary metabolites.

\section{Methods}

\section{Plant materials and treatments}

Meristem cultures of Atractylodes lancea (collected in Maoshan, Jiangsu Province, China) were established according to Wang et al. [22]. The explants were surface sterilized and grown in MS medium [23] supplemented with $0.3 \mathrm{mg} / \mathrm{L}$ naphthaleneacetic acid (NAA), $2.0 \mathrm{mg} / \mathrm{L}$ 6-benzyladenine, $30 \mathrm{~g} / \mathrm{L}$ sucrose, and $10 \%$ agar in $150 \mathrm{~mL}$ Erlenmeyer flasks. Rooting medium (1/2 MS) contained $0.25 \mathrm{mg} / \mathrm{L}$ NAA, $30 \mathrm{~g} / \mathrm{L}$ sucrose, and $10 \%$ agar. All media were adjusted to a $\mathrm{pH}$ of 6.0 before being autoclaved. Cultures were maintained in a growth chamber $\left(25 / 18^{\circ} \mathrm{C}\right.$ day/night, with a light intensity of $3400 \mathrm{~lm} /$ $\mathrm{m}^{2}$ and a photoperiod of $12 \mathrm{~h}$ ) and subcultured every four weeks. Thirty-day-old rooting plantlets were used for all treatments.

Reagents used as specific scavengers or inhibitors, including ibuprofen (IBU), nordihydroguaiaretic acid
(NDGA), 2-(4-carboxyphenyl)-4,4,5,5-tetramethylimidazoline -1-oxyl-3-oxide potassium salt (cPTIO), paclobutrazol (PAC), catalase (CAT), diphenylene iodonium (DPI), and 2-aminoindan-2-phosphonic acid (AIP), were purchased from Sigma-Aldrich (St. Louis, MO, USA). All exogenous signaling molecules and inhibitors were filtered using $0.22 \mu \mathrm{m}$ diameter microporous membranes before use. Unless stated otherwise, inhibitors were applied $1 \mathrm{~d}$ before the application of signaling molecules or fungal inoculation.

\section{Fungal culture and treatments}

The endophytic fungus AL12 (Gilmaniella sp.) was isolated from $A$. lancea, cultured on potato dextrose agar, and incubated at $28^{\circ} \mathrm{C}$ for five days [24]. Thirty-day-old plantlets were inoculated using 5-mm AL12 mycelial disks. An equal size of potato dextrose agar was used as a control. All treatments were conducted in a sterile environment and replicated at least three times to examine reproducibility.

\section{Measurement of $\mathrm{H}_{2} \mathrm{O}_{2}$ and $\mathrm{NO}$}

Thirty-day-old plants were incubated with fungal mycelia disks with or without inhibitors and were harvested $18 \mathrm{~d}$ later for determination of $\mathrm{NO}$ or $\mathrm{H}_{2} \mathrm{O}_{2}$. Inhibitors were $1.25 \mathrm{mmol} \mathrm{L}^{-1}$ cPTIO, $5.25 \mathrm{mKat} \mathrm{L}^{-1}$ CAT or $3 \mathrm{mmol}$ $\mathrm{L}^{-1} \mathrm{DPI}$.

The generation of $\mathrm{H}_{2} \mathrm{O}_{2}$ by $A$. lancea plantlets was measured by chemiluminescence in a ferricyanidecatalyzed oxidation of luminol according to Schwacke and Hager [25], with modification. Leaf samples (1 g) were ground with $5 \mathrm{ml}$ double distilled water. The homogenate was centrifuged at $13,000 \mathrm{~g}$ for $10 \mathrm{~min}$, then $100 \mu \mathrm{L}$ supernatant, $50 \mu \mathrm{L}$ luminol (5-amino-2,3-dihydro-1,4-phthalazinedione), and $800 \mu \mathrm{L}$ phosphate-buffered saline were mixed in a cuvette. The reaction was initiated with $100 \mu \mathrm{L} \quad \mathrm{K}_{3}\left[\mathrm{Fe}(\mathrm{CN})_{6}\right]$. To compare independent experiments, we used $\mathrm{H}_{2} \mathrm{O}_{2}$ as an internal standard. Fifty microliters of $\mathrm{H}_{2} \mathrm{O}_{2}(1 \mu \mathrm{M}$, freshly prepared) was added to the assay mixture containing $750 \mu \mathrm{L}$ potassium phosphate buffer. One unit of $\mathrm{H}_{2} \mathrm{O}_{2}$ was defined as the chemiluminescence caused by the internal standard of $1 \mu \mathrm{M} \mathrm{H}_{2} \mathrm{O}_{2}$ per gram fresh weight.

The generation of NO was monitored using a NO detection kit (Nanjing Jiancheng Bio-engineering Inst., Nanjing, China) according to the manufacturer's instructions. Leaf samples (1 g) were ground with $5 \mathrm{ml}$ of $40 \mathrm{mM}$ 4-(2-hydroxyethyl)-1-piperazineethanesulfonic acid ( $\mathrm{pH} 7.2$ ) and the homogenate was centrifuged at $14,000 \mathrm{~g}$ for $10 \mathrm{~min}$. The supernatant was used for the $\mathrm{NO}$ assays. One unit of NO was defined as the absorbance variation caused by the internal standard of $1 \mu \mathrm{M}$ NO per gram fresh weight. 
At least 15 plantlets were assayed for each time point, and all treatments were performed in triplicate.

\section{Measurement of SA}

Thirty-day-old plants were incubated with fungal mycelia disks with or without inhibitors and were harvested $18 \mathrm{~d}$ later for determination of SA. Inhibitors were $1 \mathrm{mmol} \mathrm{L}^{-1}$ PAC or $2.5 \mathrm{mmol} \mathrm{L}^{-1}$ AIP.

Salicylic acid was extracted followed the method of Verberne et al. [26], with some modifications. Five grams of whole plantlets was ground in liquid nitrogen and extracted in $2 \mathrm{ml}$ methanol by sonication. After centrifugation at $14,000 \mathrm{~g}$ for $5 \mathrm{~min}$, the supernatant was rotary evaporated, and the residue was resuspended in $250 \mu \mathrm{l}$ of $5 \%$ trichloroacetic acid. The mixture was re-extracted with $800 \mu \mathrm{l}$ acetic acid ester: cyclohexane $(1: 1 \mathrm{v} / \mathrm{v})$. Finally, the organic phase was rotary evaporated until dry, dissolved with $600 \mu \mathrm{l} \mathrm{HPLC}$ mobile phase (methanol: $2 \%$ acetic acid: $\mathrm{H}_{2} \mathrm{O}, 50: 40: 10, \mathrm{v}$ : v: v), and filtered with a $0.22-\mu \mathrm{m}$ microporous membrane for determination.

The SA samples were quantified by HPLC using a reverse-phase column (Hedera Packing Material Lichrospher 5-C18, 4.6 $250 \mathrm{~mm}, 5 \mu \mathrm{m}$, Bonna-Agela Technologies, Wilmington, DE, USA). The mobile phases flow rate was $1 \mathrm{ml} \mathrm{min}{ }^{-1}$. Salicylic acid was detected at $217 \mathrm{~nm}$ at $25^{\circ} \mathrm{C}[14]$.

\section{Extraction and determination of volatile oils and JA}

Thirty-day-old plantlets of Atractylodes lancea were incubated with 5-mm mycelial disks or PDA disks (control). Inhibitors (0.1 mmol L-1 IBU or NDGA) were added $1 \mathrm{~d}$ before fungal inoculation for JA determination.

Volatile oils were extracted from whole plantlets of $A$. lancea, including leaves and rhizomes $(0.8-1.6 \%$ oil content in leaves, $2.2-3.4 \%$ in rhizomes), according to Zhang et al. [27]. The volatile oils were dried with anhydrous sodium sulfate and stored in dark glass bottles at $4^{\circ} \mathrm{C}$ for gas chromatograph (GC) analysis.

Following Juergen et al. [28], JA was extracted by grinding plant material $(1 \mathrm{~g})$ frozen in liquid nitrogen and extracting with $\mathrm{H}_{2} \mathrm{O}$ : acetone (30:70, v:v). Samples were store in dark glass bottles at $-21^{\circ} \mathrm{C}$ for $\mathrm{GC}$ analysis.

GC determination was carried out using an 1890 series GC (Hewlett-Packard, Palo Alto, CA) equipped with a flame ionization detector. A DB- $5 \mathrm{~ms}(30 \mathrm{~m} \times 0.25 \mathrm{~mm} \times 0.25 \mu \mathrm{m})$ column (Agilent, Santa Clara, CA, USA) was used with the following temperature program: column held at $60^{\circ} \mathrm{C}$ for $1 \mathrm{~min}$ after injection, increased by $10^{\circ} \mathrm{C} / \mathrm{min}$ to $190^{\circ} \mathrm{C}$, held for $2 \mathrm{~min}$, increased by $5^{\circ} \mathrm{C} / \mathrm{min}$ to $210^{\circ} \mathrm{C}$, held for $2 \mathrm{~min}$, increased by $10^{\circ} \mathrm{C} / \mathrm{min}$ to $220^{\circ} \mathrm{C}$, and held for $8 \mathrm{~min}$. Nitrogen was used as carrier and the flow rate was $4 \mathrm{ml} / \mathrm{min}$. Four main components of the volatile oils, atractylone, hinesol, $\beta$-eudesmol, and atractylodin, were quantitatively analyzed according to the method of Fang et al. [29]; their retention times were $14.57,15.24,16.21$, and $22.18 \mathrm{~min}$, respectively.

\section{Real-time quantitative RT-PCR analysis}

Total RNA was extracted from leaves as described by Dong and Beer [30]. First-strand cDNA was synthesized from $1 \mu \mathrm{g}$ of total RNA (PrimeScript RT Reagent Kit, Takara, Dalian, China). Real-time qPCR was performed using the DNA Engine Opticon 2 Real-time PCR Detection System (Bio-Rad, Hercules, CA, USA) and SYBR green probe (SYBR Premix Ex Taq system, Takara). The constitutivelyexpressed gene EF1 $\alpha$ used as an internal positive control. The gene-specific primers used to amplify EF1 $\alpha$ were $5{ }^{\prime}-\mathrm{C}$

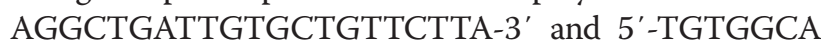
TCCATCTTGT-3' (241 bp product) and for alHMGR were $5^{\prime}$-GGTGAGAAAGGTCCTGAAA-3' and 5' -CATG GTAACGGAGATATGAA-3' (154 bp). The GenBank accession numbers of the alHMGR and EF1 $\alpha$ genes are EF090602.1 and X97131, respectively.

The thermocycler program was as follows: $90 \mathrm{~s}$ at $95^{\circ} \mathrm{C}$; 40 cycles of $30 \mathrm{~s}$ at $95^{\circ} \mathrm{C}, 30 \mathrm{~s}$ at $57^{\circ} \mathrm{C}$, and $30 \mathrm{~s}$ at $72^{\circ} \mathrm{C}$; and $5 \mathrm{~min}$ at $72^{\circ} \mathrm{C}$. To standardize the data, the ratio of the absolute transcript level of the alHMGR genes to the absolute transcript level of EF1 $\alpha$ was calculated for each sample of each treatment.

\section{Statistical analyses}

Data were compiled using Microsoft Excel (Redmond, WA, USA). The values were represented as mean \pm SD of three replicates for each treatment. Student's $t$-test, one-way ANOVA, and Duncan's multiple range test were used to identify significant differences (SPSS ver. 13.0, SPSS Inc., Chicago, IL, USA).

\section{Results}

\section{Dependence of JA in fungus-induced volatile oil} accumulation

The JA contents of the plantlets increased significantly after endophytic fungus inoculation (Figure 1A), indicating that the fungus may trigger JA biosynthesis in the plantlets. Concurrently, the total amount of volatile oils increased significantly (Table 1). Both IBU and NDGA are inhibitors of the octadecanoid pathway that synthesizes JA and are usually applied in plant systems as JAspecific inhibitors [13]. To investigate whether JA was involved in the fungus-induced volatile oil accumulation, IBU and NDGA were applied; as shown in Figure 1B, both inhibitors suppressed not only the fungus-induced JA generation, but also the fungus-triggered volatile oil production. The results suggested that JA was important for fungus-induced volatile-oil synthesis in $A$. lancea plantlets. However, volatile oils in the $A$. lancea plantlets treated with both fungus and JA inhibitors could still accumulate, compared with the control, even though JA 


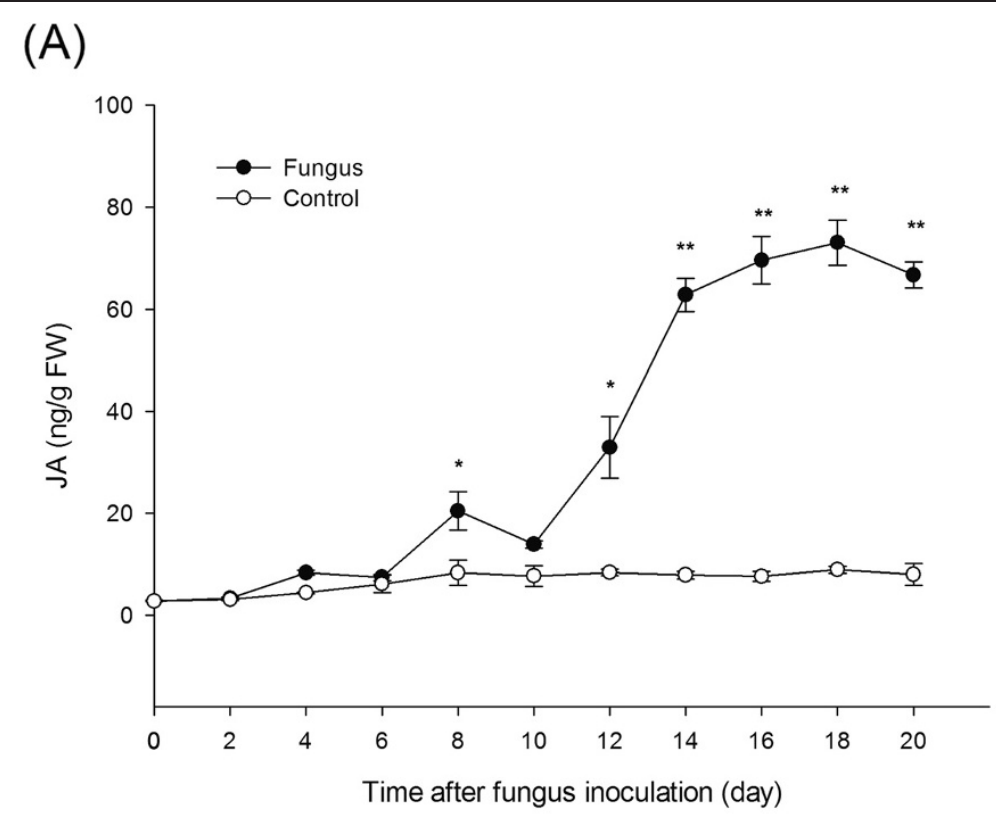

(B)

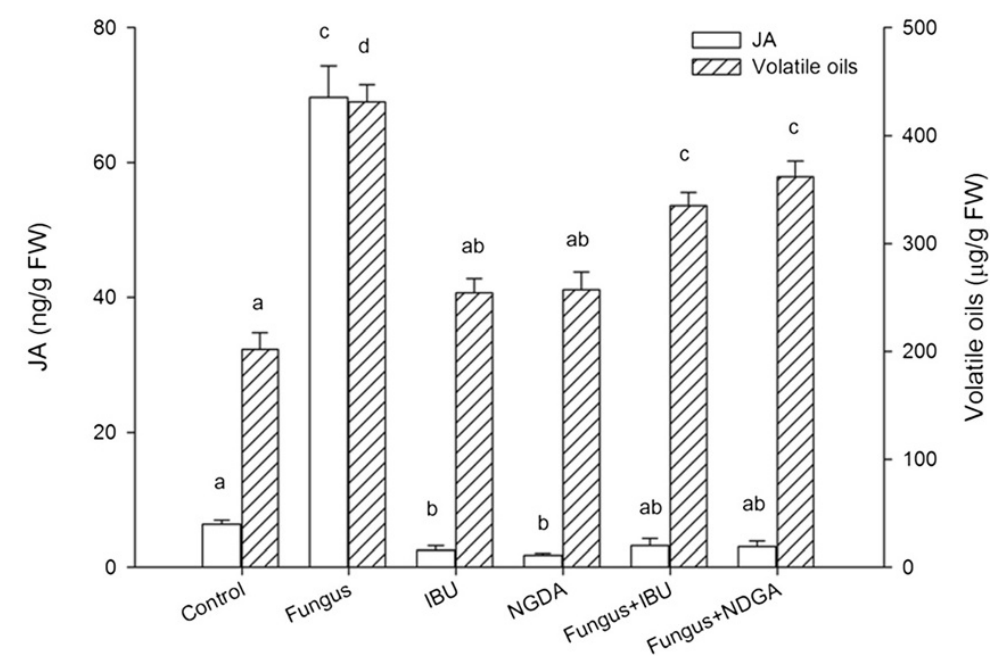

Figure 1 Endophytic fungus-induced volatile-oil accumulation is dependent on JA generation. Thirty-day-old plantlets of Atractylodes lancea were incubated with 5-mm mycelial disks or PDA disks (control). (A) Jasmonic acid production at 2-day intervals. Asterisks indicate significant differences from the control $(0 \mathrm{~d})\left(t\right.$-test; ${ }^{*}, P<0.05$; $\left.{ }^{* *}, P<0.01\right)$. (B) Effects of JA inhibitors on endophytic fungus-induced volatile-oil accumulation after $18 \mathrm{~d}$. Inhibitors $\left(0.1 \mathrm{mmol} \mathrm{L}^{-1} \mathrm{IBU}\right.$ or NDGA) were added $1 \mathrm{~d}$ before fungal inoculation. Values are means of three independent experiments. Bars with different lower-case letters were significantly different (one-way ANOVA, Duncan's multiple range test, $P<0.05$ ).

generation was lower than control (Figure 1B), implying that fungus-induced volatile oil synthesis is not solely dependent on the JA signaling pathway.

JA acts as a downstream signal of $\mathrm{NO}$ and $\mathrm{H}_{2} \mathrm{O}_{2}$ pathway Previous results showed that JA is not the sole signaling pathway involved in fungus-induced volatile oil synthesis; $\mathrm{NO}, \mathrm{H}_{2} \mathrm{O}_{2}$, and $\mathrm{SA}$ are also known to mediate this process in A. lancea plantlets [22]. To investigate a possible relationships between JA and one or more of these other pathways, A. lancea plantlets were treated with the NO-specific scavenger cPTIO, the membrane NADPH oxidase inhibitor DPI/CAT, the SA inhibitor PAC/AIP, IBU, and fungal inoculation. The NO scavenger cPTIO could inhibit JA production in inoculated plantlets, but IBU could not inhibit NO production (Figure 2A), showing that JA may act as a downstream signal of NO. Exogenous $\mathrm{H}_{2} \mathrm{O}_{2}$ could reverse JA suppression, implying that JA is mediated by $\mathrm{NO}$ though $\mathrm{H}_{2} \mathrm{O}_{2}$ in endophyte-induced volatile-oil accumulation. In 
Table 1 Accumulation of volatile oils by Atractylodes lancea over time

\begin{tabular}{|c|c|c|c|c|c|c|c|c|c|c|c|}
\hline Components & Treatment & 0 day & 4 day & 6 day & 8 day & 10 day & 12 day & 14 day & 16 day & 18 day & 20 day \\
\hline \multirow[t]{2}{*}{ Atractylone $(\mu \mathrm{g} / \mathrm{g})$} & Fungus & $4.63 \pm 1.41 a$ & $4.23 \pm 0.74 a$ & $5.24 \pm 0.94 a$ & $4.41 \pm 0.67 a$ & $4.97 \pm 0.56 a$ & $8.64 \pm 1.19 b$ & $13.48 \pm 1.54 \mathrm{c}$ & $23.53 \pm 2.76 \mathrm{~d}$ & $28.43 \pm 1.54 d$ & $15.13 \pm 0.93 c$ \\
\hline & Control & $4.63 \pm 1.27 a$ & $2 \pm 1.02 \mathrm{a}$ & $3.97 \pm 0.42 a$ & $5.2 \pm 0.55 a$ & $5 \pm 0.75 a$ & $2 \pm 0.48 a$ & $4.31 \pm 0.39$ & $4.71 \pm 0.44 a$ & $5.17 \pm 0.63 a$ & $5.6 \pm 0.52 \mathrm{a}$ \\
\hline \multirow[t]{2}{*}{ Hinesol $(\mu \mathrm{g} / \mathrm{g})$} & Fungus & $38.17 \pm 4.32 \mathrm{a}$ & $40.12 \pm 3.82 \mathrm{a}$ & a & $40.85 \pm 5.63 a$ & o & 1 & $d$ & e & $128 \pm 9.42 f$ & b \\
\hline & Control & $38.17 \pm 5.36 a$ & $32.31 \pm 3.52 \mathrm{a}$ & $38.63 \pm 3.78 a$ & $35.62 \pm 3.29 a$ & $43.81 \pm 4.22 \mathrm{a}$ & $46.95 \pm 3.04 a$ & $37.13 \pm 6.27 a$ & $46.21 \pm 3.23 a$ & $46.9 \pm 3.32 a$ & $50.22 \pm 5.24 a$ \\
\hline \multirow[t]{2}{*}{$\beta$-Eudesmol ( $\mu \mathrm{g} / \mathrm{g})$} & Fungus & $80.72 \pm 11.37 a$ & $85.6 \pm 6.01 a$ & $92.23 \pm 6.43 a$ & $96.63 \pm 6.48 b$ & $104.75 \pm 6.12 c$ & $104.75 \pm 6.06 c$ & $116.58 \pm 6.19 d$ & $119.62 \pm 6.25 e$ & $123.83 \pm 8.07 e$ & $99.65 \pm 4.18 c$ \\
\hline & Control & $80.72 \pm 10.75 a$ & $78.7 \pm 8.32 \mathrm{a}$ & $81.27 \pm 8.53 \mathrm{a}$ & $88.51 \pm 7.95 a$ & $93.18 \pm 8.28 a$ & $94.67 \pm 8.05 a$ & $98.38 \pm 5.04 a$ & $96.42 \pm 8.15 a$ & $85.1 \pm 8.18 \mathrm{a}$ & $94.77 \pm 7.84 a$ \\
\hline \multirow[t]{2}{*}{ Atractylodin $(\mu \mathrm{g} / \mathrm{g})$} & Fungus & $98.32 \pm 14.53 a$ & $109.24 \pm 11.31 a$ & $111.23 \pm 12.95 a$ & $118.97 \pm 12.74 a$ & $125.53 \pm 17.85 a$ & $131.52 \pm 12.34 a$ & $137.64 \pm 15.31 b$ & $152.34 \pm 12.92 b$ & $171.63 \pm 12.04 b$ & $183.4 \pm 12.39 c$ \\
\hline & Control & $98.32 \pm 12.75 a$ & $110.7 \pm 10.61 a$ & $114.2 \pm 7.76 a$ & $115.42 \pm 8.23 a$ & $121.9 \pm 10.28 a$ & $111.47 \pm 12.71 a$ & $116.8 \pm 10.07 a$ & $118.5 \pm 10.63 a$ & $121.1 \pm 10.75 a$ & $134.1 \pm 10.68 a$ \\
\hline \multirow[t]{2}{*}{ Total $(\mu \mathrm{g} / \mathrm{g})$} & us & $4 \pm 31.63 a$ & $9 \pm 21.88 a$ & $\pm 25.25 \mathrm{a}$ & $\pm 25.52 b$ & $=28.76 \mathrm{C}$ & $4.87 d$ & 34 & $.15 f$ & $07 \mathrm{~g}$ & $21.95 \mathrm{e}$ \\
\hline & Control & $221.84 \pm 30.13 a$ & $226.63 \pm 23.47 a$ & $238.07 \pm 20.49 a$ & $244.75 \pm 19.77 a$ & $262.04 \pm 23.53 a$ & $257.01 \pm 24.28 a$ & $256.62 \pm 21.77 a$ & $265.84 \pm 22.45 a$ & $258.27 \pm 22.85 a$ & $284.69 \pm 24.28 a$ \\
\hline
\end{tabular}

Thirty-day-old plantlets were incubated with 5 -mm mycelia disks or with an equal size of potato dextrose agar (control). Data are mean \pm standard deviation (SD) of triplicate samples. Within each row, values followed by different lower-case letters were significantly different (one-way ANOVA, Duncan's multiple range test, $P<0.05$ ). 

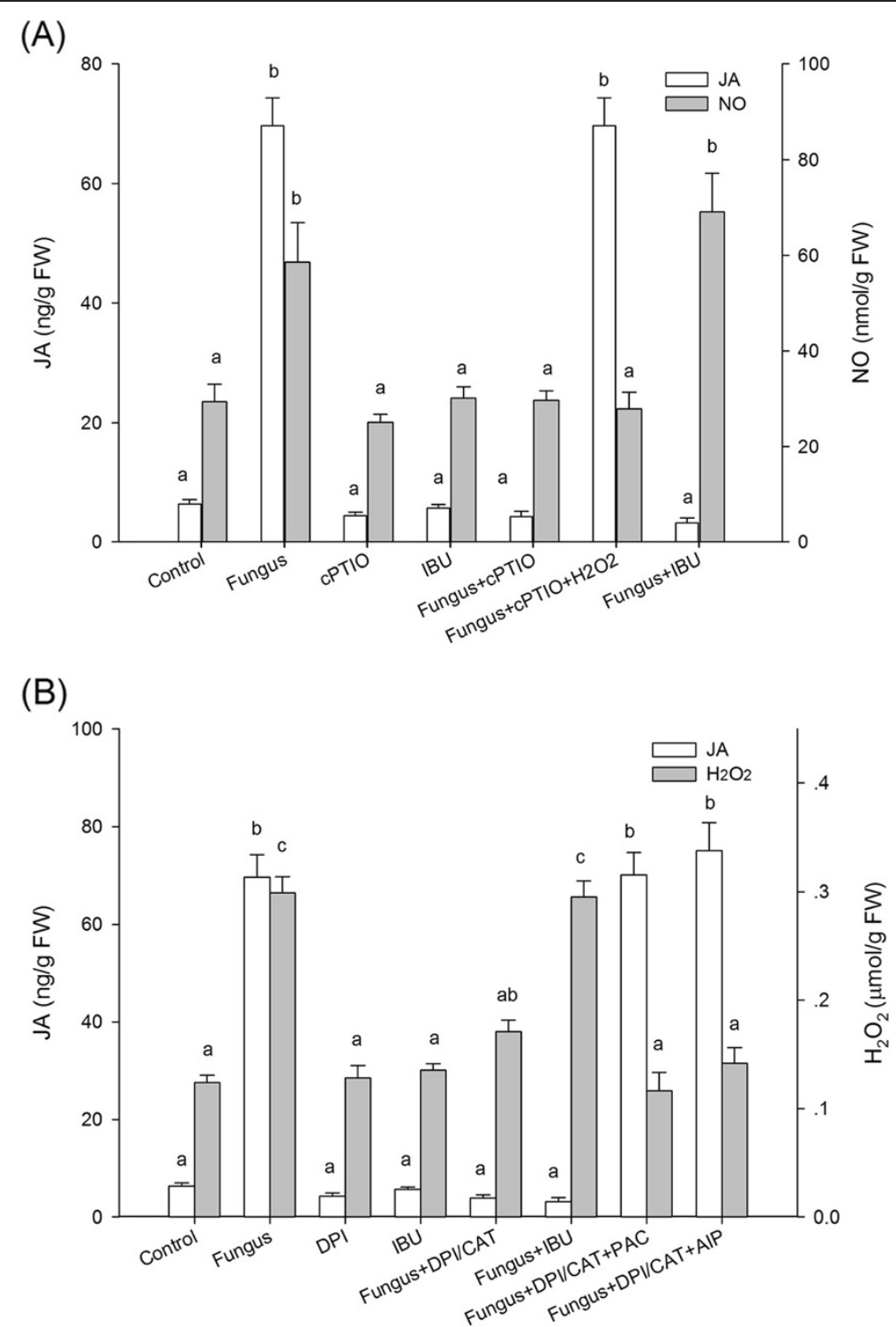

Figure 2 Interactions between JA and $\mathrm{NO}$ or $\mathrm{H}_{2} \mathrm{O}_{2}$ signaling pathways induced by endophytic fungus. Thirty-day-old plantlets of Atractylodes lancea were incubated with 5-mm mycelia disks with or without inhibitors and were harvested $18 \mathrm{~d}$ later for determination of JA and $\mathrm{NO}$ or $\mathrm{H}_{2} \mathrm{O}_{2}$ concentrations. (A) Interactions between JA and NO pathways. Inhibitors were $1.25 \mathrm{mmol} \mathrm{L} \mathrm{C}^{-1} \mathrm{CPTIO}_{0} 0.1 \mathrm{mmol} \mathrm{L}^{-1} \mathrm{IBU}$, or $15 \mathrm{mmol}^{-1}$ $\mathrm{H}_{2} \mathrm{O}_{2}$. (B) Interactions between $\mathrm{JA}$ and $\mathrm{H}_{2} \mathrm{O}_{2}$. Inhibitors were 3 mmol L-1 DPI, $5.25 \mathrm{mKat} \mathrm{L}^{-1}$ CAT, $0.1 \mathrm{mmol} \mathrm{L} \mathrm{L}^{-1} \mathrm{BU}, 1 \mathrm{mmol} \mathrm{L}^{-1} \mathrm{PAC}$, or $2.5 \mathrm{mmol} \mathrm{L}^{-}$

${ }^{1}$ AIP. All inhibitors were added $1 \mathrm{~d}$ before fungus inoculation. Values are means of three independent experiments. Bars with different lower-case letters were significantly different (one-way ANOVA, Duncan's multiple range test, $P<0.05$ ).

addition, the $\mathrm{H}_{2} \mathrm{O}_{2}$ inhibitor DPI/CAT could inhibit JA production, but IBU could not inhibit $\mathrm{H}_{2} \mathrm{O}_{2}$ production with inoculation (Figure 2A). The one-way dependence of JA on $\mathrm{H}_{2} \mathrm{O}_{2}$ confirmed that $\mathrm{H}_{2} \mathrm{O}_{2}$ was the intermediary factor between JA and NO.

Paclobutrazol is an effective SA biosynthesis-related benzoic acid hydroxylase (BA2H) inhibitor [31] that also inhibits gibberellin biosynthesis [32]. Therefore, we also used AIP, a specific SA biosynthesis-related phenylalanine ammonialyase (PAL) inhibitor [33,34], to confirm that SA generation was suppressed. Interestingly, PAC and AIP could abolish the suppression of JA by DPI/ CAT with fungus inoculation (Figure 2B). This result implied that the SA and JA signaling pathways were closely linked in endophyte-induced volatile-oil accumulation in A. lancea plantlets.

\section{Complementary interactions between JA and SA in} fungus-induced volatile-oil accumulation

To further investigate the relationship between JA and SA, gradient concentrations of the JA-inhibiter IBU and the SA-inhibitors PAC and AIP were applied. As shown 


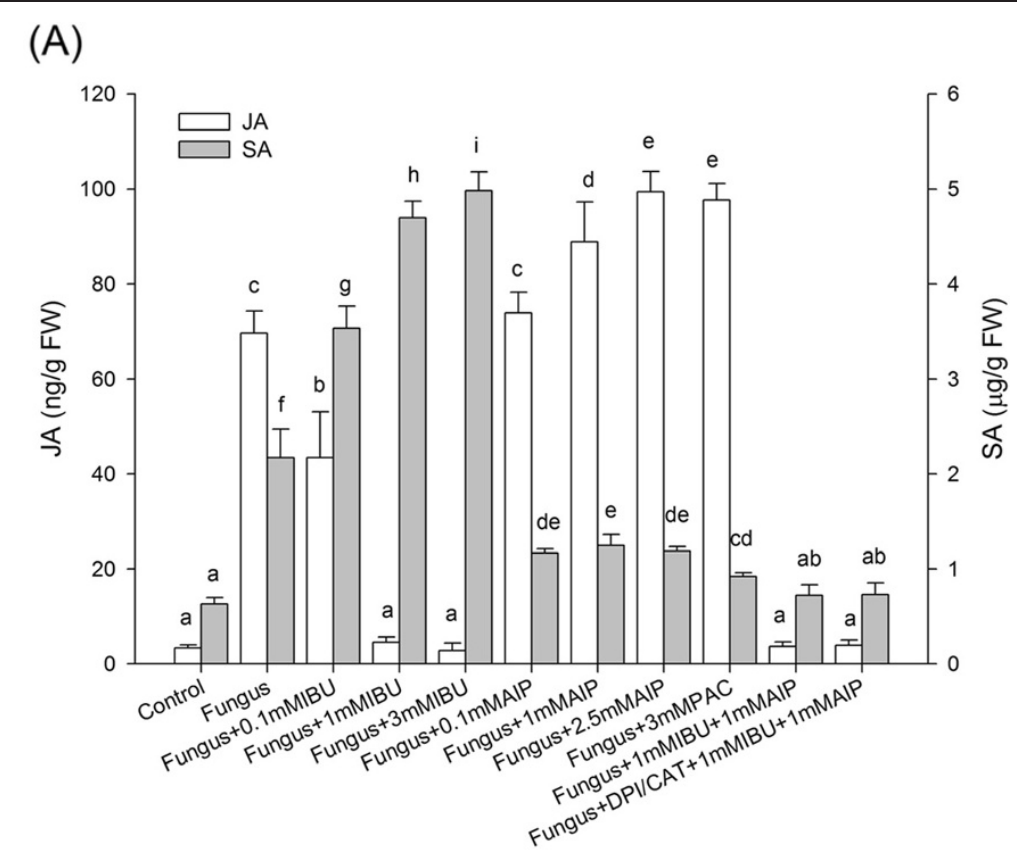

(B)

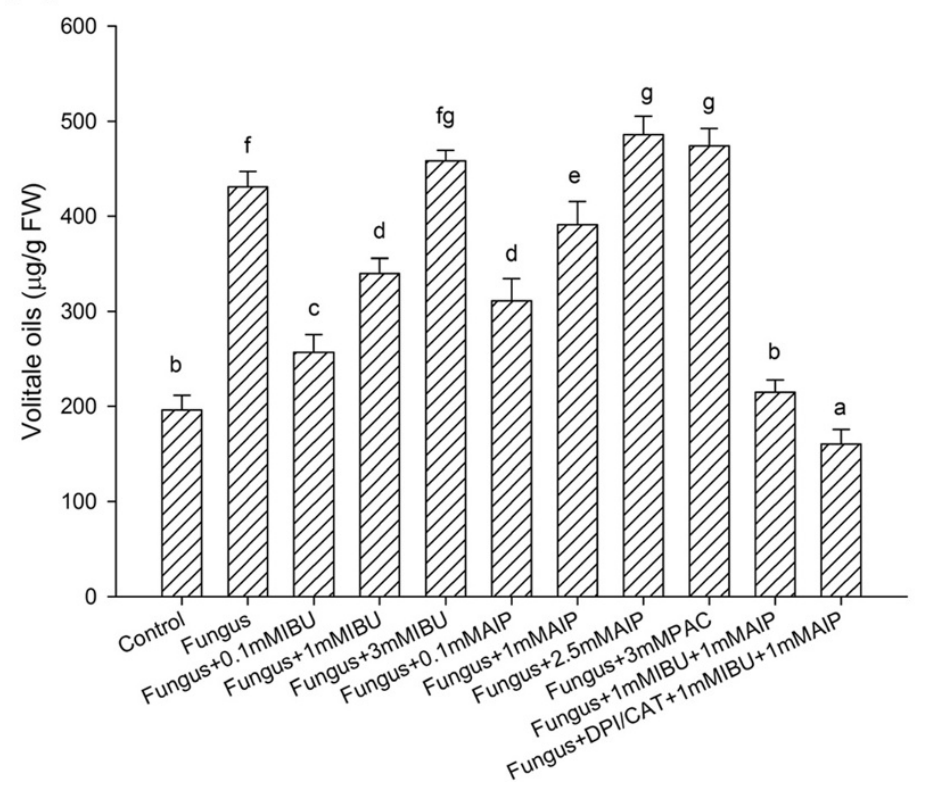

Figure 3 Complementary interaction between JA and SA signaling pathways induced by endophytic fungus. Thirty-day-old plantlets of Atractylodes lancea were incubated with 5- $\mathrm{mm}$ mycelia disks and 0.1 , 1, or $3 \mathrm{mmol} \mathrm{L}{ }^{-1} \mathrm{IBU} ; 3 \mathrm{mmol} \mathrm{L}{ }^{-1} \mathrm{DPl}$; or 0.1 , 1, or $2.5 \mathrm{mmol} \mathrm{L}^{-1} \mathrm{AlP}$ and $3 \mathrm{mmol} \mathrm{L}^{-1}$ PAC. Plants were harvested $18 \mathrm{~d}$ later to determine JA and volatile oil levels. Inhibitors were added $1 \mathrm{~d}$ before fungus inoculation. (A) Interactions between JA and SA pathways. (B) Volatile oil production. Values are means of three independent experiments. Bars with different lower-case letters were significantly different (one-way ANOVA, Duncan's multiple range test, $P<0.05$ ).

in Figure 3, the fungus-induced JA level of the plantlets decreased gradually as IBU concentration increased, but both SA accumulation and volatile oil content were enhanced as well, although the amounts did not exceed those obtained with fungal inoculation alone. Similarly,
SA levels in plantlets were inhibited by $0.1,1$, and $2.5 \mathrm{mmol} \mathrm{L}^{-1}$ AIP and by $3 \mathrm{mmol} \mathrm{L}^{-1}$ PAC, whereas JA was enhanced significantly (Figure $3 \mathrm{~A}$ ). Volatile oil accumulation was enhanced by $2.5 \mathrm{mmol} \mathrm{L}^{-1}$ AIP and $3 \mathrm{mmol} \mathrm{L}^{-1}$ PAC (Figure 3B). The results suggested that 


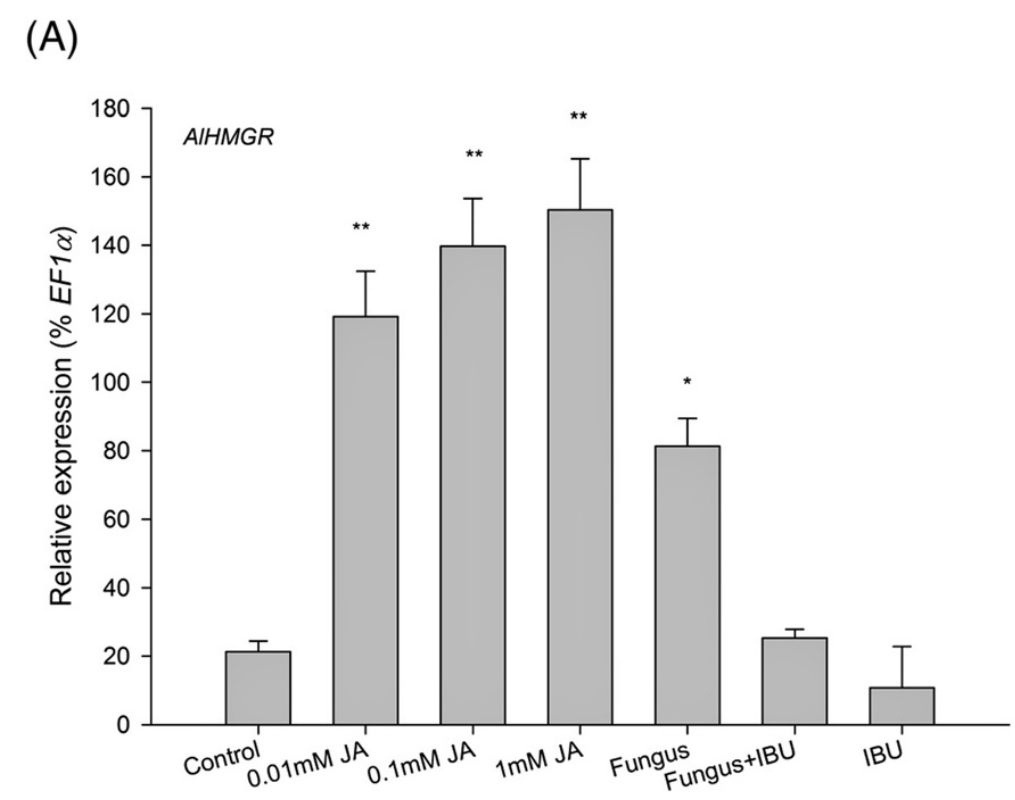

(B)

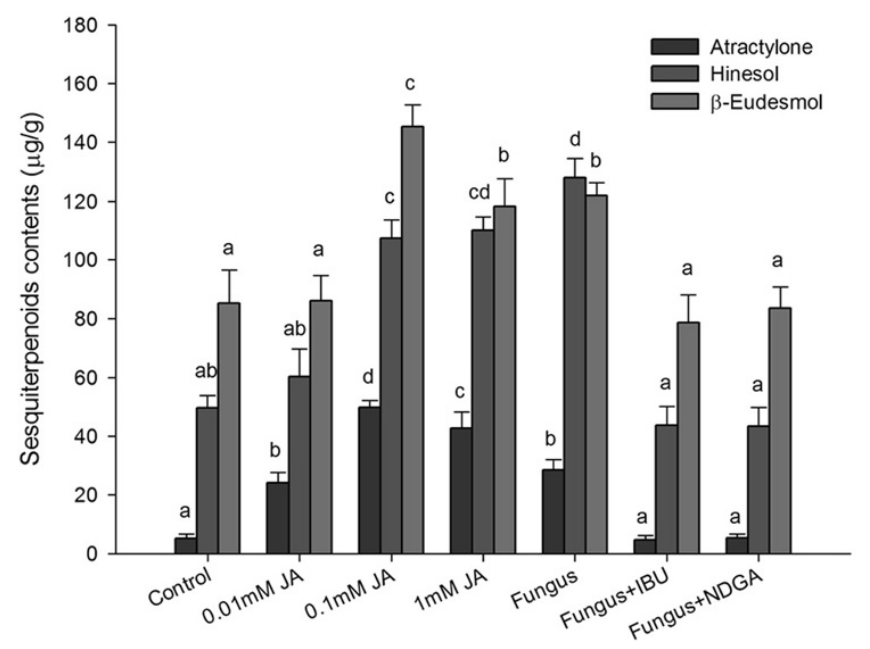

Figure 4 Expression levels of HMGR genes and sesquiterpenoid accumulation responses to JA signaling pathway. (A) Expression levels of EF1a and HMGR genes in response to JA determined by real-time qPCR and semi-qPCR analysis. Thirty-day-old plantlets of Atractylodes lancea were incubated with 5-mm mycelia disks; $0.01,0.1$, or $1 \mathrm{mmol} \mathrm{L}^{-1} \mathrm{JA}$; or $1 \mathrm{mmol} \mathrm{L}^{-1} \mathrm{IBU}$ and harvested $18 \mathrm{~d}$ later for total RNA extraction and PCR analysis. Values are means \pm SE $(n=3)$. Asterisks indicate significant differences ( $t$-test; $\left.{ }^{*}, P<0.05 ;{ }^{* *}, P<0.01\right)$. (B) Effects of JA on sesquiterpenoid accumulation. Plantlets were harvested after $18 \mathrm{~d}$ and evaluated for atractylone, $\beta$-eudesmol, and hinesol content. Values are means $\pm S E(n=3)$. Bars with different lower-case letters were significantly different (one-way ANOVA, Duncan's multiple range test, $P<0.05$ ).

JA may have a complementary interaction with SA to mediate fungal endophyte-induced volatile-oil accumulation. However, combining IBU and paclobutrazol could not completely inhibit volatile oil synthesis. We added the $\mathrm{H}_{2} \mathrm{O}_{2}$-inhibitor DPI/CAT to IBU and paclobutrazol, which reduced volatile-oil accumulation to the level of the control. The results suggested that $\mathrm{H}_{2} \mathrm{O}_{2}$, SA, and JA may work simultaneously in fungus-induced volatile-oil synthesis in A. lancea plantlets.

\section{Dependence of fungus-induced sesquiterpenoid production on JA production}

The enzyme 3-hydroxy-3-methylglutaryl-CoA reductase (HMGR) catalyzes the conversion of HMG-CoA to mevalonate, which is the key step in the terpenoid biosynthesis pathway in plants $[35,36]$. We further investigated the possible mediating role of JA on HMGR gene expression. The results showed that exogenous JA could strongly stimulate HMGR gene expression (Figure 4A). Three sesquiterpenoid 


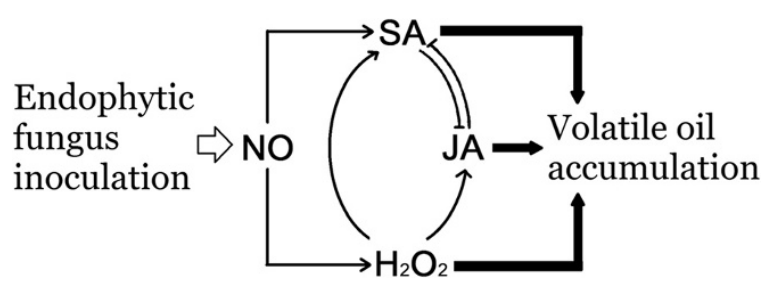

Figure 5 Cross-talk between signaling pathways for volatile oil accumulation induced by endophytic fungal elicitor. "indicates that the signal molecule was suppressed by specific inhibitors, while positive regulation is shown as".

components of $A$. lancea volatile oils, atractylone, $\beta$-eudesmol, and hinesol, were all induced by JA and suppressed by IBU with fungal inoculation (Figure 4B).

\section{Discussion}

Secondary metabolite accumulation is a common plant response to biotic or abiotic environmental stress, and secondary messengers are widely employed to mediate the accumulation of plant secondary metabolites. This work demonstrated that the fungus Gilmaniella sp. can induce JA production and promote the accumulation of volatile oils in host plantlets. As an important signal molecule, JA plays key roles in regulating the induction of volatile oils by the endophytic fungus. The specific inhibitors IBU and NDGA could block the JA signaling pathway and reduce the accumulation of related metabolites. Our previous study showed that $\mathrm{NO}, \mathrm{H}_{2} \mathrm{O}_{2}$, and $\mathrm{SA}$ acted as signal molecules to mediate the accumulation of volatile oils in suspension cells of $A$. lancea caused by endophytic fungal elicitor [22]. Thus, the possible relationships between JA and other known signaling pathways in the accumulation of secondary metabolites were further investigated.

Cross-talk between different signal transduction pathways, as opposed to single signaling pathways, mediates gene expression and the production of secondary metabolites during plant defense responses [37,38]. Hydrogen peroxide has been reported to be a possible upstream signal for NO production in mung bean plantlets [39]. Nitric oxide also can mediated fungal elicitor-induced taxol biosynthesis in Taxus chinensis suspension cells through reactive oxygen signaling pathways, stimulate SA accumulation in tobacco cell cultures, and induce PAL expression via an SA independent pathway [31,40,41]. Moreover, our previous work demonstrated that NO mediates volatile oil accumulation induced by the fungus through SA- and $\mathrm{H}_{2} \mathrm{O}_{2}$-dependent pathways. Hydrogen peroxide can enhance SA production but does not act as upstream signal molecule [22]. The present work showed that endophytic fungus-induced JA was directly mediated by $\mathrm{H}_{2} \mathrm{O}_{2}$ and acted as a downstream signal molecule for both $\mathrm{H}_{2} \mathrm{O}_{2}$ and $\mathrm{NO}$ pathways.

In our study, JA had an unusual complementary interaction with the SA signaling pathway. Jasmonic acid is commonly postulated to act antagonistically on the SA signaling pathway and on the expression of SA-dependent genes $[42,43]$. Other studies have shown that SA is a potent suppressor of JA signaling pathways and JAdependent defense gene expression in various pharmacological and genetic experiments [44,45]. In addition, both JA and SA are important signaling molecules in plant defense responses, such as the activation of distinct sets of defense-related genes and the development of systemic acquired resistance $[21,46]$. Our results showed that when JA biosynthesis was suppressed by the inhibitor IBU, accumulation of SA was enhanced to compensate for the loss of JA-mediating function in fungus-triggered volatile-oil production. Similarly, JA production/signaling could substitute for the SA pathway when SA accumulation was impaired.

\section{Conclusions}

The value of medicinal herbs relies mainly on the accumulation of active pharmaceutical ingredients; low yield is the main challenge to producing high-quality herbs. In this work, we demonstrated that JA acts as a downstream signaling molecule in $\mathrm{NO}$ - and $\mathrm{H}_{2} \mathrm{O}_{2}$-mediated volatile oil accumulation induced by endophytic fungus and has a complementary interaction with the SA signaling pathway and clarified that HMGR gene expression was significantly stimulated by JA along with increasing sesquiterpenoid components. This information will help to better understand the relationships between fungal endophytes and their host plants. Furthermore, it also suggests strategies to improve the quality of medicinal herbs.

\section{Competing interests \\ The authors declare that they have no competing interests.}

\section{Authors' contributions}

CGR designed experiment, analyzed data, and wrote the manuscript. CCD supervised the work and interpreted data with CGR. Both authors read and approved the final manuscript.

\section{Acknowledgements}

The authors are grateful to the National Natural Science Foundation of China (grant nos. 31070443 and 30500066) and a project funded by the Priority Academic Program Development of Jiangsu Higher Education Institutions for financial support. 
Received: 27 June 2012 Accepted: 25 July 2012

Published: 2 August 2012

\section{References}

1. Duan JA, Wang LY, Qian SH, Su SL, Tang YP: A new cytotoxic prenylated dihydrobenzofuran derivative and other chemical constituents from the rhizomes of Atractylodes lancea DC. Arch Pharm Res 2008, 31(8):965-969.

2. Yuan Y, Liu YJ, Huang LQ, Cui GH, Fu GF: Soil acidity elevates some phytohormone and $\beta$-Eudesmol contents in Roots of Atractylodes lancea. Russ J Plant Physiol 2009, 56(1):133-137.

3. Wang $Y$, Dai CC, Chen Y: Antimicrobial activity of volatile oil from Atractylodes lancea against three species of endophytic fungi and seven species of exogenous fungi. Chinese J Appl Ecol 2009, 20(11):2778-2784. in Chinese.

4. Rodriguez RJ, White JJF, Arnold AE, Redman RS: Fungal endophytes: diversity and functional roles. New Phytol 2009, 182(2):314-330.

5. Mucciarelli M, Camusso W, Maffei M, Panicco P, Bicchi C: Volatile terpenoids of endophyte-free and infected peppermint (Mentha piperita L.): chemical partitioning of a symbiosis. Microb Ecol 2007, 54(4):685-696.

6. Wang AM, Zhang FK, Huang LF, Yin XP, Li HF, Wang QY, et al: New progress in biocatalysis and biotransformation of flavonoids. J Med Plants Res 2010, 4(10):847-856.

7. John MM, Jeffery LD: Signal transduction in the plant immune response. Trends in biochemical science 2000, 25(2):x79-82.

8. Hahlbrock K, Bednarek P, Ciolkowski I, Hamberger B, Heise A, Liedgens $H$, Logemann E, Nurnberger T, Schmelzer E, Somssich IE, Tan JW: Non-self recognition, transcriptional reprogramming, and secondary metabolite accumulation during plant/pathogen interactions. Proc Natl Acad Sci USA 2003, 100 (Suppl 2):14569-14576.

9. Ward ER, Uknes SJ, Williams SC, Dincher SS, Wiederhold DL, Alexander DC, Ahl-Goy P, Métraux JP, Ryals JA: Coordinate gene activity in response to agents that induce systemic acquired resistance. Plant Cell 1991, 3 (10):1085-1094.

10. Kazan K, Manners JM: Jasmonate signaling: toward an integrated view. Plant Physiol 2008, 146(4):1459-1468.

11. Van LC, Van EA: The families of pathogenesis related proteins, their activities, and comparative analysis of PR-1 type proteins. Physiol. Molec. Plant Pathol. 1999, 55(2):85-97.

12. Yuan $Y, L i C$, Hu Z: Signal transduction pathway for oxidative burst and taxol production in suspension cultures of Taxus chinensis vat mairei induced by oligosaccharide from Fusarium oxysprum. Enzyme Microb Technol 2001, 29(7):372-379.

13. Nojiri $H$, Sugimori M, Yamane $H$, Nishimura $Y$, Yamada A, Shibuya $N$, Kodama O, Murofushi N, Omori T: Involvement of jasmonic acid in elicitor-induced phytoalexin production in suspension-cultured rice cells. Plant Physiol 1996, 110(2):387-392.

14. Gao FK, Ren CG, Dai CC: Signaling Effects of Nitric Oxide, Salicylic Acid, and Reactive Oxygen Species on Isoeuphpekinensin Accumulation in Euphorbia pekinensis Suspension Cells Induced by an Endophytic Fungal Elicitor. J Plant Growth Regul 2012, doi:10.1007/s00344-012-9258-8.

15. Suryanarayanana TS, Thirunavukkarasub N, Govindarajulub MB, Sassec F, Jansend R, Muralia TS: Fungal endophytes and bioprospecting. Fungal Biology Reviews. 2009, 23(2):9-19.

16. Wang LW, Xu BG, Wang JY, Su ZZ, Lin FC, Zhang CL, Kubicek CP: Bioactive metabolites from Phoma species, an endophytic fungus from the Chinese medicinal plant Arisaema erubescens. Applied Microbial and Cell Physiology 2012, 93(3):1231-1239.

17. Saunders M, Kohn LM: Evidence for alteration of fungal endophyte community assembly by host defense compounds. New Phytol 2009, 182 (1):229-238

18. Li YC, Tao WY: Interactions of taxol-producing endophytic fungus with its host (Taxus spp.) during taxol accumulation. Cell Biol Int 2009, 33(1):106-112.

19. Halim VA, Vess A, Scheel D, Rosahl S: The Role of Salicylic Acid and Jasmonic Acid in Pathogen Defence. Plant Biol 2006, 8(2):307-313.

20. Zhao J, Davis LC, Verpoorte R: Elicitor signal transduction leading to production of plant secondary metabolites. Biotechnol Adv 2005, 23 (4):283-333.

21. Kunkel BN, Brooks DM: Cross talk between signaling pathways in pathogen defense. Curr Opin Plant Biol 2002, 5(4):325-331.

22. Wang Y, Dai CC, Zhao YW, Peng Y: Fungal endophyte-induced volatile oil accumulation in Atractylodes lancea plantlets is mediated by nitric oxide, salicylic acid and hydrogen peroxide. Process Biochem 2011, 46 (3):730-735.

23. Murashige T, Skoog F: A revised medium for rapid growth and bioassays with tobacco tissue culture. Physiol Plant 1962, 15(3):473-479.

24. Chen JX, Dai CC, Li X, Tian LS, Xie H: Endophytic fungi screening from Atracty lancea and inoculating into the host plantlet. Guihaia 2008, 28 (2):256-260.

25. Schwacke $R$, Hager $A$ : Fungal elicitors induce a transient release of active oxygen species from cultured spruce cells that is dependent on $\mathrm{Ca}^{2+}$ and protein-kinase activity. Planta 1992, 187(1):136-141.

26. Verberne MC, Brouwer N, Delbianco F, Linthorst HJM, Bol HF, Verpoorte R: Method for the extraction of the volatile compound salicylic acid from tobacco leaf material. Phytochem Anal 2002, 13(1):45-50.

27. Zhang B, Dai CC, Fang F, Chen JX: Effects of three species endophytic fungi on Atractylodes lancea growth and its essential oil composition. Chin J Ecol 2009, 28:704-709. in Chinese.

28. Juergen E, Eric AS, Hans TA, Yasmin JC, Juan H, James HT: Simultaneous quantification of jasmonic acid and salicylic acid in plants by vaporphase extraction and gas chromatography-chemical ionization-mass spectrometry. Anal Biochem 2003, 312(2):242-250.

29. Fang F, Dai CC, Zhang B, Liang QL: Establishment of suspension cell line of Atractylodes lancea and effect of endophytic fungal elicitors on its essential oil accumulation. Chin Tradit Herbal Drugs 2009, 40(3):452-455. in Chinese

30. Dong H, Beer SV: Riboflavin induces disease resistance in plants by activating a novel signal transduction pathway. Phytopathology 2000, 90 (8):801-811.

31. Leon J, Lawton MA, Raskin L: Hydrogen peroxide stimulates salicylic acid biosynthesis in tobacco. Plant Physiol 1995, 108(4):1637-1678.

32. Shiow YW, Tung S, Miklos F: Translocation of Paclobutrazol, a Gibberellin Biosynthesis Inhibitor, in Apple Seedlings. Plant Physiol 1986, 82(1):11-14

33. Zon J, Amrhein N: Inhibitors of phenylalanine ammonia-lyase:2aminoindan-2- phosphonic acid and related compounds. Eur J Org Chem 1992, 6:625-628.

34. Willibald S, Naoko K, Dieter S: The decisive step in betaxanthin biosynthesis is a spontaneous reaction. Plant Physiol 1999, 119(4):12171232.

35. Chappell J, Wolf F, Proulx J, Cuellar R, Saunders C: Is the reaction catalyzed by 3-hydroxyl-methylglutaryl coenzyme $A$ reductase a rate-limiting step for isoprenoid biosynthesis in plants? Plant Physio/ 1995, 109(4):1337-1343.

36. Ha SH, Kim JB, Hwang YS, Lee SW: Molecular characterization of three 3hydroxy-3-methylglutaryl -CoA reductase genes including pathogeninduced $\mathrm{Hmg} 2$ from pepper (Capsicum annuum). Biochimica et Biophys. Acta 2003, 1625(3):253-260.

37. Reymond P, Farmer EE: Jasmonate and salicylate as global signals for defense gene expression. Curr Opin Plant Biol 1998, 1(5):404-411.

38. Mur LAJ, Kenton P, Atzorn R, Miersch O, Wasternack C: The outcomes of concentration-specific interactions between salicylate and jasmonate signaling include synergy, antagonism, and oxidative stress leading to cell death. Plant Physiol 2006, 140(1):249-262.

39. Lum HK, Butt YKC, Lo SCL: Hydrogen peroxide induces a rapid production of nitric oxide in Mung bean (Phaseolus aureus). Nitric Oxide-Biol Ch 2002, 6(2):205-213.

40. Chamnongpol S, Willekens H, Moeder W, Langebartels C, Sandermann H Jr, Van MM, Inzé D, Van CW: Defense activation and enhanced pathogen tolerance induced by $\mathrm{H}_{2} \mathrm{O}_{2}$ in transgenic tobacco. Proc Natl Acad Sci USA 1998, 95(10):5818-5823.

41. Xu MJ, Dong JF, Zhu MY: Nitric oxide mediates the fungal elicitorinduced Taxol biosynthesis of Taxus chinensis suspension cells through the reactive oxygen species-dependent and -independent signal pathways. Chin Sci Bull 2006, 51(2):1967-1975.

42. Kachroo P, Shanklin J, Shah J, Whittle EJ, Klessig DF: A fatty acid desatuase modulates the activation of defense signaling pathways in plants. Proc Natl Acad Sci USA 2001, 98(16):9448-9453.

43. Kloek AP, Verbsky ML, Sharma SB, Schoelz JE, Vogel J, Klessig DF, Kunkel BN: Resistance to Pseudomonas syringae conferred by an Arabidopsis thaliana coronatineinsensitive (coil) mutation occurs through two distinct mechanisms. Plant J 2001, 26(5):509-522.

44. Steven HS, Annemart K, Susanne M, Claessens C, Jerôme PK, Johan AVP, Martin JM, Antony JB, Jean-Pierre M, Rebecca B, Kemal K, Van Loon LC, Xinnian D, Corné MJP: NRP1 modulates cross-talk between salicylate- and 
jasmonate dependent defense pathways through a novel function in the cytosol. Plant Cell 2003, 15(3):60-770.

45. Li J, Brader G, Palva ET: The WRKY70 transcription factor: a node of convergence for jasmonate-mediated and salicylate-mediated signals in plant defense. Plant Cell 2004, 16(2):319-331.

46. Shah J: The salicylic acid loop in plant defense. Curr Opin Plant Biol 2003 6(4):365-371.

doi:10.1186/1471-2229-12-128

Cite this article as: Ren and Dai: Jasmonic acid is involved in the signaling pathway for fungal endophyte-induced volatile oil accumulation of Atractylodes lancea plantlets. BMC Plant Biology 2012 $12: 128$

\section{Submit your next manuscript to BioMed Central and take full advantage of:}

- Convenient online submission

- Thorough peer review

- No space constraints or color figure charges

- Immediate publication on acceptance

- Inclusion in PubMed, CAS, Scopus and Google Scholar

- Research which is freely available for redistribution 